\title{
Occupational exposure to amorphous silica dust and pulmonary function
}

\author{
D Choudat, C Frisch, G Barrat, A El Kholti, F Conso
}

\begin{abstract}
Respiratory manifestations among 41 workers exposed to amorphous silica dust were compared with a control group comprising 90 workers of equivalent socioeconomic state in the same plant. Flow volumes were determined, blood gas concentrations were measured at rest and during exercise, chest radiographs were obtained, and data about respiratory symptoms were collected by questionnaire. A dust exposure index was calculated for each exposed worker. It was not possible to differentiate between the two groups from the questionnaire, blood gas analysis, or chest radiographs. On the other hand, the tests of respiratory function showed a significant decrease in forced expiratory flow $\left(\right.$ FEF $_{25-75}$, FEF $_{50}$, and FEF $\left._{75}\right)$ in the exposed group compared with the controls, although no correlation was found between the exposure index and pulmonary function. It appears that smoking and exposure to amorphous silica synergise to induce small airway disease.
\end{abstract}

It is well known that exposure to crystalline silica can induce pneumoconiosis. The fibrogenic effects of amorphous silica are currently being investigated and a few cases of pulmonary fibrosis have been reported after exposure of workers to amorphous silica dust. ${ }^{12}$ By contrast, many experimental studies with amorphous silica have shown little biological effect. One epidemiological survey did not find respiratory symptoms, ventilatory impairment, or radiographic evidence of pneumoconiosis among a group of 165 workers exposed to precipitated amorphous silica. ${ }^{3}$

The purpose of this study was to determine the pulmonary effects of occupational exposure to amorphous silica compared with a control group. Also,

\footnotetext{
Département de médecine du travail, Faculté Cochin-Port-Royal, 24, rue du faubourg SaintJacques, 75014 Paris, France D Choudat, C Frisch, G Barrat, A El Kholti, F Conso
}

blood gas concentrations, at rest and during exercise, were evaluated as possible indicators of changes in lung function as a result of exposure.

\section{Subjects and methods}

POPULATION

The study population was composed of workers at a large chemical plant engaged in the synthesis of amino acids and vitamins. One hundred and thirty one men worked in three shifts for continuous production. The first shift was from 4 am to 12 noon, the second from 12 noon to $8 \mathrm{pm}$, and the third from 8 pm to $4 \mathrm{am}$. The shifts alternated each week. The workers were divided in two groups according to exposure in their current job. Group E comprised 41 workers exposed or previously exposed to silica. The mean duration of exposure was eight years (range 128 years). Group $\mathrm{C}$ was a control group and comprised 90 workers of equivalent socioeconomic state in the same plant. They were not exposed to appreciable air contaminants in the plant and were matched for age with group $E$. The data, except chest radiograph and dust assessment, were collected during a week in May 1988.

\section{QUESTIONNAIRE}

A questionnaire, which took about 10 minutes to complete, was presented by trained interviewers. It included questions about individual characteristics such as age, height, weight, race, medical history, and work history in the plant and before employment in the plant. Non-smokers were defined as those persons smoking less than one cigarette a day and exsmokers as those who had stopped smoking completely at least six months before the study. Questions on respiratory symptoms were adapted from the questionnaire of the International Union Against Tuberculosis and Lung Disease.

\section{TESTS OF PULMONARY FUNCTION}

Measurement of pulmonary function was carried out at the work site using a computerised pneumotachograph Fleish No 3 (Spiromatic, MSR), which was calibrated daily. Forced expiration was assessed on an oscilloscope. At least three readings were obtained with the worker seated and wearing a noseclip. The curve producing the largest sum of forced expiratory volume in one second $\left(\mathrm{FEV}_{1}\right)$ and 
forced vital capacity (FVC) was selected for analysis. Other standard parameters of pulmonary function (forced expiratory flow (FEF) ${ }_{25-75}, \mathrm{FEF}_{25}, \mathrm{FEF}_{50}$, and $\mathrm{FEF}_{75}$ ), were recorded from this best maximal expiratory flow volume curve. All values were adjusted for age and height using regressions on the whole sample and normalised (mean $(\mathrm{SD})=0(1)$ ). In the figures normalised values are presented for subjects of mean population age (42, SD 8 years) and height $(172$, SD $7 \mathrm{~cm})$.

\section{BLOOD GAS CONCENTRATIONS AT REST AND DURING EXERCISE}

Samples for blood gas analysis were taken from the earlobe after vasodilatation with Finalgon (Boehringer Ingelheim) 10 minutes before the first incision. Arterial blood was collected in heparinised capillary tubes and immediately analysed by a trained technician with Corning 170 apparatus.

Concentrations of blood gases were measured at rest after the questionnaire, and after spirometry during standardised exercise on a treadmill (Gymroll 1000 , Gillet). Heart rate was continuously monitored by electrocardiography (Tec 7100, MSR). The mean duration of the exercise was about seven minutes. When heart rate reached 130 beats a minute, samples for blood gas analysis were collected again and analysed by the same technician. Exercise was not performed by subjects with cardiac or rheumatic conditions (12 in group $\mathrm{C}$ and 10 in group $\mathrm{E}$ ).

\section{CHEST RADIOGRAPHS}

Posteroanterior chest radiographs $(8 \times 8 \mathrm{~cm})$ were obtained at a different time from the interview. They were read by three independent physicians according to the International Labour Office classification.

\section{ASSESSMENT OF ENVIRONMENTAL EXPOSURE}

About thirty tonnes a day of precipitated amorphous silica containing $3.8 \%$ of respirable dust were used in the plant.

Levels of dust exposure were appraised in the working area using a CIP 10 individual sampler. The duration of each sampling was 340 minutes. Thirty six samplings were made while the workers were actually performing their jobs. Total dust concentrations ranged from 0 to $10.5 \mathrm{mg} / \mathrm{m}^{3}$. Respirable dust concentrations ranged from 0 to $3.4 \mathrm{mg} / \mathrm{m}^{3}$.

An exposure index was calculated for each worker according to the quantity and the duration of exposure to amorphous silica. For each worker, time spent in the presence of amorphous silica was evaluated. This time was multiplied by three if it occurred before 1984. Three was chosen because dust measurements were three times greater before 1984, after which a better system of ventilation was established in the working area.
STATISTICAL ANALYSIS

Contingency tables $(2 \times 2)$ with $\chi^{2}$ tests were used to determine whether relations shown between variables were statistically significant. Quantitative variables were compared by $t$ test. Analysis of variance was used to examine the relation of respiratory symptoms, work exposure, and smoking to pulmonary function.

\section{Results}

Smoking habits and characteristics of the population did not differ significantly between the two groups except for the percentage of shiftworkers (table 1). Table 2 shows the prevalence of respiratory symptoms.

Concentrations of blood gas at rest and during exercise were not significantly different between group E and group C (table 3), and no difference was found between the chest radiographs of the two groups.

All air flow values were lower in group $E$ than in group $C$ (table 4 and fig 1) with significant differences for $\mathrm{FEV}_{1} / \mathrm{FVC}, \mathrm{FEF}_{25-75}, \mathrm{FEF}_{50}$, and $\mathrm{FEF}_{75}$. There was no significant correlation, however, between the exposure index and pulmonary function.

Results of the pulmonary function tests were compared according to the exposure to tobacco and

Table 1 Characteristics of control workers (group C) and workers exposed to amorphous silica (group E)

\begin{tabular}{lccl}
\hline & Group C & Group E & p Value \\
\hline No of subjects & 90 & 41 & \\
Age (y; mean (SD)) & $42(8)$ & $42(9)$ & NS \\
Height (cm; mean (SD)) & $174(7)$ & $174(7)$ & NS \\
Weight (kg; mean (SD)) & $77(10)$ & $79(13)$ & NS \\
Shift workers (No (\%)) & $55(61)$ & $36(87)$ & $<0 \cdot 01$ \\
Smokers (No (\%)) & $38(42)$ & $19(46)$ & NS \\
Ex-smokers (No(\%)) & $23(25)$ & $9(22)$ & NS \\
Non-smokers (No (\%)) & $29(32)$ & $13(31)$ & NS \\
\hline
\end{tabular}

Table 2 Prevalence of respiratory symptoms in controls (group C) and workers exposed to amorphous silica (group E)

\begin{tabular}{lccl}
\hline & $\begin{array}{c}\text { Group C } \\
\text { No }(\%)\end{array}$ & $\begin{array}{c}\text { Group } E \\
\text { No }(\%)\end{array}$ & p Value \\
\hline Morning cough & $8(8 \cdot 9)$ & $7(17)$ & NS \\
Usual cough & $8(8 \cdot 9)$ & $5(12 \cdot 2)$ & $<0.001$ \\
Attack of coughing & $15(16.7)$ & $5(12 \cdot 2)$ & NS \\
Phlegm & $5(5.6)$ & $4(9.8)$ & NS \\
Shortness of breath & $3(3.3)$ & $2(4.9)$ & NS \\
Wheezing & $12(13.3)$ & $2(4.9)$ & $<0.001$ \\
Tightness & $9(10)$ & $3(7.3)$ & $<0.05$ \\
Dyspnoea grade 1 & $19(21 \cdot 1)$ & $16(39)$ & $<0.001$ \\
Dyspnoea grade 2 & $0(0)$ & $1(2.4)$ & NS \\
Statement about breathing: & $78(86.7)$ & $35(85.4)$ & NS \\
$\quad$ Good & $9(10)$ & $2(4.9)$ & NS \\
Medium & $3(3.3)$ & $4(9.8)$ & NS \\
Bad & $2(2.2)$ & $4(9.8)$ & $<0.001$ \\
Asthma & & & \\
\hline
\end{tabular}


to amorphous silica (figs 2 and 3). The mean values of $\mathrm{FEF}_{75}, \mathrm{FEF}_{50}$, and $\mathrm{FEF}_{25-75}$ were lower among the smokers and the exposed workers than among the non-smoking non-exposed workers. These differences were significant between the smoking-exposed group and the non-smoking non-exposed group.

Table 3 Blood gas concentrations at rest and during exercise in control workers (group C) and workers exposed to amorphous silica (group E)

\begin{tabular}{|c|c|c|c|}
\hline & $\begin{array}{l}\text { Group C } \\
\text { Mean (SD) }\end{array}$ & $\begin{array}{l}\text { Group } E \\
\text { Mean }(S D)\end{array}$ & p Value \\
\hline $\begin{array}{l}\mathrm{PaO}_{2} \text { at rest }(\mathrm{mm} \mathrm{Hg}) \\
\mathrm{PaCO}_{2} \text { at rest }(\mathrm{mm} \mathrm{Hg}) \\
\mathrm{PaO}_{2} \text { during exercise }(\mathrm{mm} \mathrm{Hg}) \\
\mathrm{PaCO}_{2} \text { during exercise }(\mathrm{mm} \mathrm{Hg}) \\
\text { Heart rate at rest (beats/min })\end{array}$ & $\begin{array}{l}78 \cdot 1(6 \cdot 7) \\
38(2 \cdot 2) \\
78(8 \cdot 7) \\
40(2 \cdot 8) \\
83(12 \cdot 6)\end{array}$ & $\begin{array}{l}77 \cdot 2(6 \cdot 7) \\
38 \cdot 7(2 \cdot 4) \\
79 \cdot 3(7 \cdot 2) \\
40 \cdot 1(3 \cdot 3) \\
80(12 \cdot 5)\end{array}$ & $\begin{array}{l}\text { NS } \\
\text { NS } \\
\text { NS } \\
\text { NS } \\
\text { NS }\end{array}$ \\
\hline $\begin{array}{l}\text { (beats/min) } \\
\text { Duration of exercise (min) }\end{array}$ & $\begin{array}{l}126(5 \cdot 4) \\
6 \cdot 2(1 \cdot 8)\end{array}$ & $\begin{array}{l}126(7 \cdot 6) \\
6.9(1 \cdot 8)\end{array}$ & $\begin{array}{l}\text { NS } \\
\text { NS }\end{array}$ \\
\hline
\end{tabular}

Table 4 Pulmonary function in controls (group C) and workers exposed to amorphous silica (group E)

\begin{tabular}{|c|c|c|c|}
\hline & $\begin{array}{l}\text { Group } C \\
\text { Mean }(S D)\end{array}$ & $\begin{array}{l}\text { Group E } \\
\operatorname{Mean}(S D)\end{array}$ & p Value \\
\hline 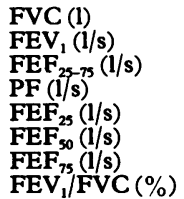 & $\begin{array}{r}4.8(0.8) \\
3.9(0.6) \\
4.2(1.2) \\
10.7(1.6) \\
8.7(1.8) \\
5.1(1.5) \\
1.8(0.7) \\
82.1(5.6)\end{array}$ & $\begin{array}{r}4.8(0.8) \\
3.8(0.6) \\
3.6(1.2) \\
10.3(1.5) \\
8.2(1.6) \\
4.5(1.4) \\
1.4(0.5) \\
79.2(5.7)\end{array}$ & $\begin{array}{l}\text { NS } \\
\text { NS } \\
<0.01 \\
\text { NS } \\
\text { NS } \\
<0.03 \\
<0.008 \\
<0.007\end{array}$ \\
\hline
\end{tabular}

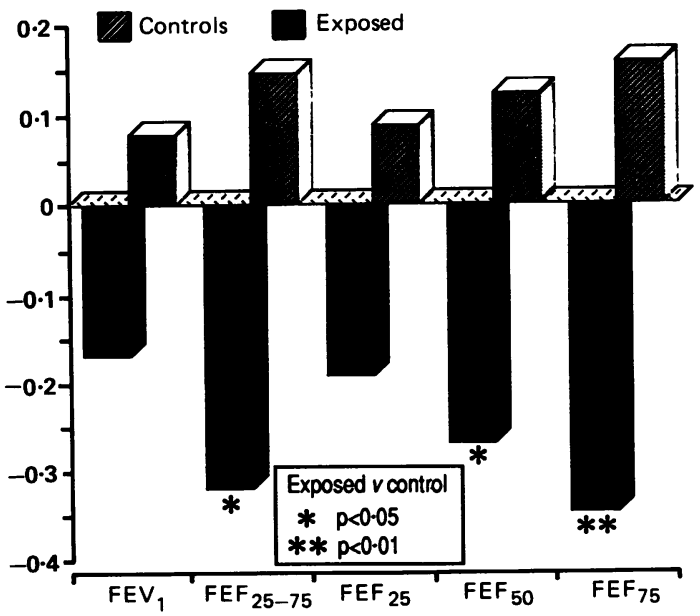

Figure 1 Mean normalised values for pulmonary function (observed-predicted values/residual SD) according to exposure. The values are adjusted for age and height.

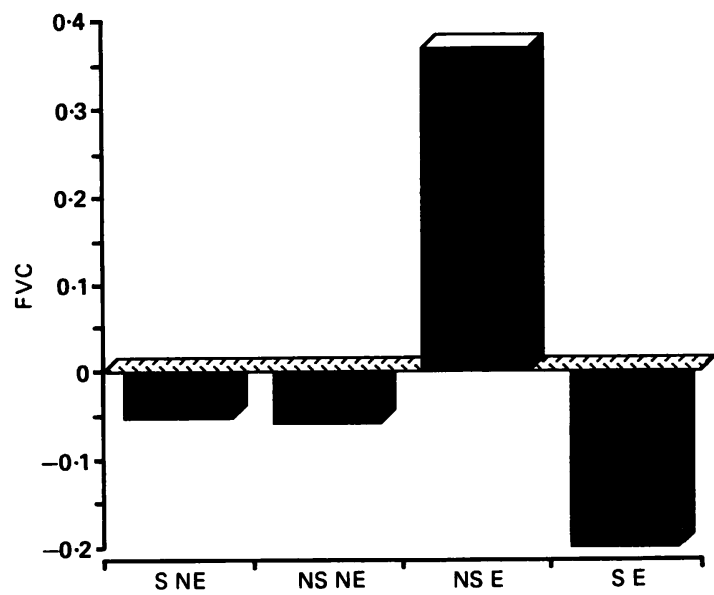

Figure 2 Mean normalised FVC according to exposure and smoking habits. $S=$ Smokers, $N S=$ non-smokers, $E=$ exposed workers, $N E=$ non-exposed workers.
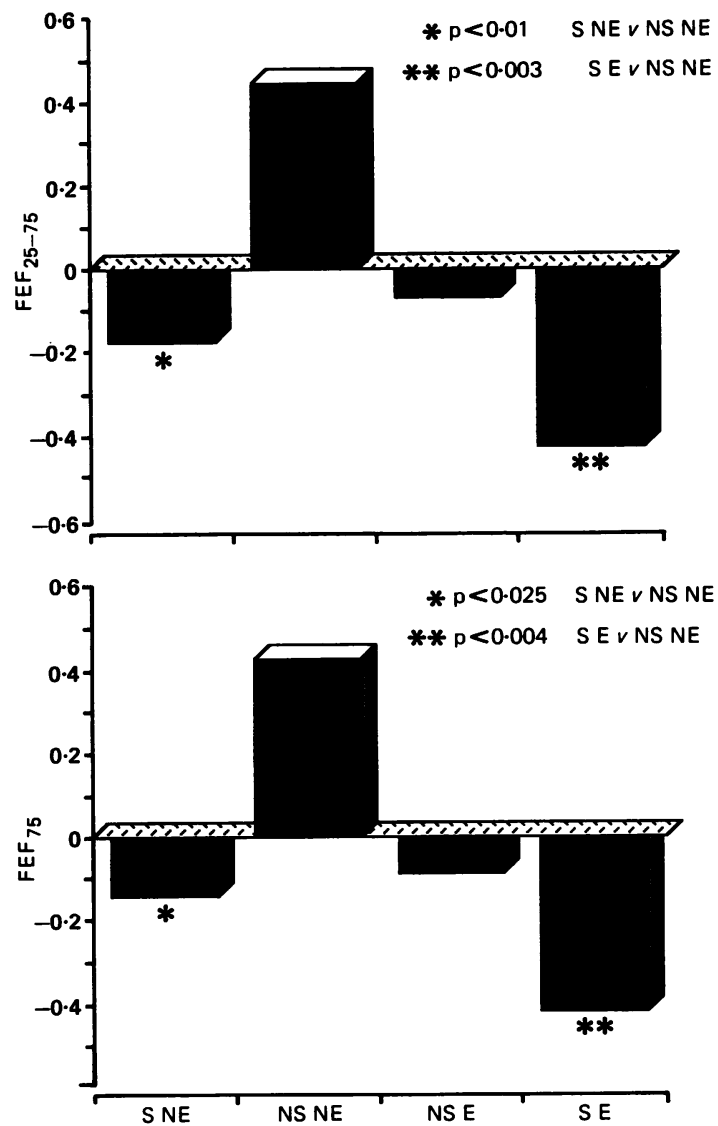

Figure 3 Mean normalised $F E F_{75 \%}$ and $F E F_{25-75 \%}$ according to exposure and smoking habits. $S=S$ mokers, $N S=$ non-smokers, $E=$ exposed workers, $N E=$ nonexposed workers. 


\section{Discussion}

Previous experimental and epidemiological studies found few effects of exposure to amorphous silica dust on respiratory function. Amorphous silica, however, is a generic term for various forms of silica such as diatomite, fused silica, and precipitated silica, which are not equally pathogenic; the present study has shown that exposure to precipitated silica dust also induces little respiratory impairment. An effect was found only by comparison between an exposed group and a control group. Wilson et al studied 165 workers exposed to precipitated amorphous silica. ${ }^{3}$ They found no relation between respiratory symptoms, tests of pulmonary function, or chest radiograph findings and the exposure to amorphous silica, but the study did not include a control group and $\mathrm{FEF}_{50}$ and $\mathrm{FEF}_{75}$ were not measured. In the present study the difference was found for $\mathrm{FEF}_{50}$, $\mathrm{FEF}_{75}$, and $\mathrm{FEF}_{25-75}$. Furthermore, the small airway disease was increased by cigarette smoking. The positive interaction between the two agents appeared to be synergistic rather than additive (fig 3 ) and may explain the emphysema found in two workers by Vitums et al. ${ }^{1}$

A further noteworthy finding was the apparent healthy worker effect of exposure to dust; the nonsmoking exposed workers having a greater FVC than the non-exposed workers (fig 2).

A further aspect of this study was our interest in the questionnaire, chest $x$ ray films, and concentrations of arterial blood gas to distinguish two groups of workers, exposed or not. None were able to discriminate.

Arterial blood gas concentrations have been proposed as an epidemiological tool to study coal workers ${ }^{45}$ but the technique had not previously been used at the work site to study lung function in subjects exposed. Several factors may explain the lack of difference in our study; amorphous silica is less fibrogenic than crystalline silica; the dust is not highly respirable and no pneumoconiosis was found on the chest radiographs of the exposed workers; the exercise regime was perhaps too weak in our study, but it was difficult to conduct a more rigorous exercise at the work site.

In conclusion, exposure to amorphous silica dust may induce a mild small airway disease, only shown by comparison with a control group. This obstruction to air flow is increased by cigarette smoking. Only flow volume curves were different between the groups. Arterial blood gases, at rest and during a standardised exercise, and chest radiographs were similar between groups.

We thank Mrs C Gimenez, F Pillière, and G Abadia for technical help, P Brochard, J Ameille, and J F Dessanges for advice, and Mrs B Najac for typing the manuscript and producing the figures. We also thank Mrs M Bidet, B Gaillot, and M Ligocki. The study was supported by a grant from Comités Départementaux contre les Maladies Respiratoires et la Tuberculose (No 88-MR/5).

1 Vitums VC, Edwards MJ, Niles NR, Borman JO, Lowry RD. Pulmonary fibrosis from amorphous silica dust, a product of silica vapor. Arch Environ Health 1977;32:62-8.

2 Brambilla C, Brambilla E, Rigaud D, Perdrix A, Paramelle B, Fourcy A. Pneumoconiose aux fumées de silice amorphe. Etude minéralogique et ultrastructurale de 6 cas. Revue française des Maladies Respiratoires 1980;8:383-91.

3 Wilson RK, Stevens PM, Lovejoy HB, Bell ZG, Richie RC. Effects of chronic amorphous silica exposure on sequential pulmonary function. J Occup Med 1979;21:399-402.

4 Smidt U, Worth G, Bielert D. Lung function and clinical findings in cross. sectional and longitudinal studies in coal workers from the Ruhr Area. International Archives of Occupational and Environmental Health 1977;40:45-70.

5 Serra R, Minette A. Contribution à l'étude des plaintes de dyspnée chez les mineurs de charbon. Deuxième Partie: Validation des mesures de gaz sanguins sur sang artérialisé au lobe de l'oreille. Revue de l'Institut d'Hygiene des Mines 1981;36:41-50.

Accepted 3 April 1990 